\title{
LAS "SEMILLAS" DE LA DISCORDIA DEL DESARROLLO GEOGRÁFICO DESIGUAL: O POR QUÉ LOS INCAS NO CONQUISTARON EUROPA
}

\section{ANTONIO BeLLISARIO*}

\section{RESUMEN}

¿Cuáles son las causas de los indiscutibles diferentes niveles de desarrollo observables entre las diversas culturas y sociedades del mundo? Algunas de las explicaciones tradicionales a este puzzle han invocado diferencias biológicas o raciales cuando otras han confiado en diferencias culturales o contingencia histórica como las causas del desigual desarrollo de la historia humana. En este artículo analizamos el argumento presentado por Jared Diamond en Guns, Germs, and Steel: The Fates of Human Societies, donde él discute, convincentemente, cómo los factores geográficos y ambientales entre los continentes fueron los elementos decisivos. El factor más importante para entender la historia humana es la producción de alimentos, o la domesticación de plantas y animales. Las sociedades que crearon un sistema eficiente de producción de alimentos se desarrollaron más rápidamente; después produjeron la escritura, la tecnología, el gobierno y la religión -como también los gérmenes y las armas de guerra-y posteriormente se aventuraron hacia los cuatro puntos cardinales de la Tierra para conquistar y destruir las culturas ágrafas. El nacimiento de la urbanización comenzó en la media luna fértil mucho antes que en otra parte del globo, debido a la presencia de una gran diversidad de plantas y animales domesticables. Entonces, la desigual distribución geográfica de plantas y animales domesticables (más que cualquier superioridad inherente de sus habitantes) condujo a que el Medio Oriente se transformara en la "cuna de la civilización". Sin embargo, otras partes del mundo nunca tuvieron esta oportunidad. Unas no tenían plantas nativas que pudieran ser domesticadas; otras tenían muy pocas y las comenzaron a cultivar muy tarde, de modo que fueron sobrepasadas abrumadoramente por los

* Profesor Asociado Departamento de Geografía, Universidad de Concepción, Concepción, Chile. Profesor Invitado, Department of Urban and Regional Planning, California State Polythectnic University, Pomona, EE.UU. E-mail: abellisario@udec.cl; antoniob@csupomona.edu 
descendientes de los euroasiáticos que ya habían comenzado a urbanizarse hace unos 9.000 años.

Palabras claves: Desarrollo desigual, Eurasia, agricultura, domesticación de animales, gérmenes de enfermedades.

\section{ABSTRACT}

What are the factors for the differing development rates of the world's societies since the Neolithic revolution? Many argue for biological, "racial" differences while others stress cultural differences or historical contingency as leading causes for the uneven development of human history. In this article we engage with the argument presented by Jared Diamond in Guns, Germs, and Steel: The Fates of Human Societies, where he convincingly argues for ecological and geographical differences between the continents as the fundamental causes. The central key to understanding human history is food production, or the domestication of plants and animals. Those societies that secured food production were able to produce reliable food surpluses, which allowed urban and stratified societies to come into existence. And then, they developed culture, technology, government, as well as nasty germs and potent weapons of war-and adventured on sea and land to conquer and decimate preliterate cultures. The rise of cities and civilization happened in Eurasia (the Fertile Crescent) long before it happened elsewhere in great part because of the presence of so many domesticable plants and animals. This, rather than any innate superiority of its inhabitants, led to its becoming the "cradle of civilization". Other peoples of the world never had a chance. Either they had no suitable plants at all, or had too few, and began farming too late, and so they were overwhelmed by the descendants of the Eurasians who had begun to urbanize 9,000 years ago.

Keywords: Unequal development, Eurasia, agriculture, animal domestication, germs and illness.

Recibido: 03.03.2006. Aceptado: 21.06.2006.

¿P OR QUE fueron los euroasiáticos los que se desarrollaron más tempranamente y terminaron concentrando una gran parte de la riqueza y del poder geopolítico mundial? ¿Por qué específicas sociedades dominan otras? ¿Por qué fueron los europeos los que conquistaron el Nuevo Mundo y colonizaron Africa? En resumen, ¿cuáles son las causas de los indiscutibles diferentes niveles de desarrollo observables entre las diversas culturas y sociedades del mundo? Estas son las preguntas que guían la investigación del profesor Jared Diamond en el valioso libro, Guns, Germs, and Steel: The Fates of Human Societies, ganador del premio Pulitzer en el año $1998^{1}$. Diamond expresa que la investigación que dio origen al libro fue gatillada por una pregunta que un político guineano le hizo en 1972, a sa-

${ }^{1}$ Jared Diamond es un reputado especialista en las áreas de biología evolutiva y biogeografía. Fue profesor de fisiología en la Escuela de Medicina de la UCLA. Actualmente es profesor en el Departamento de Geografía de la misma universidad. 
ber: ¿por qué los blancos (europeos y los americanos) desarrollaron tanto "cargamento" de bienes materiales y lo trajeron a Nueva Guinea, pero los guineanos tenían tan poco "cargamento"? ${ }^{2}$ Fue una pregunta que el autor no pudo responder a pesar de su aparente simplicidad. Y, como él lo dice, se paso cinco años intentando entender la razón. El autor usa una batería de argumentos desarrollados en los últimos años por la arqueología, la biosociología, la biología molecular, la agricultura, la inmunología, y por muchas otras disciplinas para proponer un sistema explicativo coherente de la evolución histórica de la humanidad como especie civilizada, que abarca unos 13.000 años.

Algunas de las explicaciones tradicionales a este puzzle han invocado diferencias culturales o contingencia histórica. Otras han confiado en la superioridad racial europea, una noción moralmente repugnante y refutada científicamente. A pesar de la evidencia científica acumulada en contra de esta posición (que atribuye los diferentes niveles de éxitos políticos y económicos alcanzados por las diversas culturas y grupos étnicos del mundo a las diferencias biológico-raciales), muchos persisten en perpetuar esta posición evolucionista. Además, esta teoría continúa presentando un problema obvio para los científicos que creen en la igualdad racial. ¿ Si no hay un grupo más inteligente que otro, por qué fueron los europeos, en vez de los africanos, los que desarrollaron el capitalismo industrial y fisionaron el átomo? ¿Por qué los australianos no inventaron la aritmética?

El profesor Diamond discute, convincentemente, cómo los factores geográficos y ambientales fueron los elementos decisivos que explican las diferencias de poder y riqueza entre las culturas del mundo así como el desarrollo moderno. El autor sostiene que las sociedades que superaron tempranamente la etapa de cazadores-recolectores y crearon un sistema eficiente de producción de alimentos (la domesticación de plantas y animales), y se desarrollaron más rápidamente, después produjeron la escritura, la tecnología, el gobierno y la religión -como también los gérmenes y las armas de guerra-y posteriormente se aventuraron hacia los cuatro puntos cardinales de la Tierra para conquistar y destruir las culturas ágrafas. Así, pues, el autor describe brillantemente cómo una serie de ventajas casuales condujeron al temprano desarrollo de las civilizaciones euroasiáticas.

El autor no cree que las diferencias de desarrollo entre las culturas, o entre individuos, son el resultado de diferencias innatas o genéticas. Por el contrario, Diamond explícitamente intenta probar que los factores raciales no desempeñaron un papel determinante en el desarrollo. El autor es un ambientalista en el sentido más terminante. Al contrario de los genetistas o evolucionistas, que atribuyen típicamente diferencias de grupo a los facto-

\footnotetext{
${ }^{2}$ En Nueva Guinea todos los bienes materiales y adelantos tecnológicos aportados por los colonizadores europeos recibieron colectivamente el nombre de "cargamento".
}

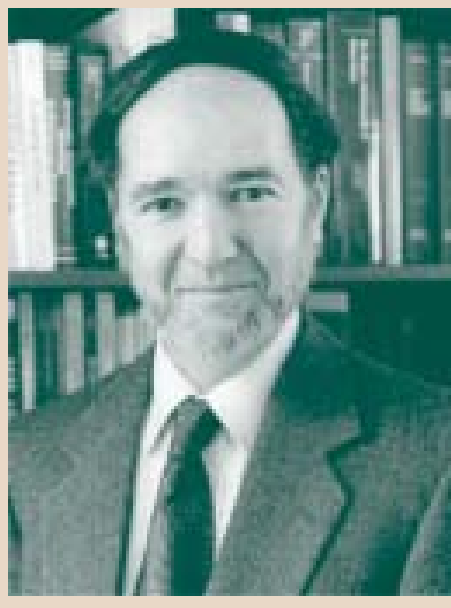

J. Diamond 
res genéticos, él considera sólo los factores medioambientales -principalmente las plantas, fauna y la geografía- como los elementos determinantes del desarrollo. Para él, los genes no explican ninguna de las variaciones en tecnología, educación, éxito militar u otros aspectos de las diversas culturas y grupos étnicos.

Diamond asume, implícitamente, que todos los grupos humanos tienen una inteligencia media idéntica, pues al momento de realizarse los cambios fundamentales del neolítico que marcaron el desarrollo sociocultural del hombre moderno, la evolución genética de éste ya se había completado hace muchos miles de años. Para Diamond, la trayectoria específica de desarrollo que cierta cultura o grupo étnico haya llevado a cabo en cualquier parte de la corteza terrestre estará determinada por la cantidad y la clase de plantas y de animales susceptibles de ser domesticados, que la región haya tenido originalmente. Y, más aun, por la configuración geográfica del territorio: si ésta permite o no una fácil y rápida difusión y adaptación de los adelantos tecnológicos. En particular, para el autor, las ventajas únicas que en dichos tres aspectos tuvo la famosa media luna fértil después de la última edad de hielo (hace 13.000 años) fue el accidente decisivo en la historia de la humanidad.

Diamond pone en guardia al lector sobre la manera como la geografía de Eurasia favoreció el temprano desarrollo de la civilización. Primero, el continente euroasiático tiene modestas barreras geográficas o un menor aislamiento interno que Australasia (con sus miles de islas en el Pacífico sur), Africa y América, lo que facilitó una rápida migración y difusión de nuevas tecnologías entre Asia y Europa. Segundo, el eje continental este-oeste de Eurasia exigió una relativa homogeneidad ecológica, que favoreció la adaptación de las fuentes domesticadas de alimentos (las diversas especies de plantas y animales domesticados) y de las enfermedades (los gérmenes). Como sabemos, los cultivos y el hábitat de los animales son altamente dependientes del clima. La franja latitudinal subtropical templada de Eurasia tiene climas más o menos similares en largas distancias, lo que facilitó la fácil difusión y adaptación de tecnologías inventadas a lo ancho de esta región. Por ejemplo, un patrón de agricultura desarrollado (digamos) en el Medio Oriente pudo adaptarse exitosamente a las condiciones ecológicas del Valle del Indo o en la meseta ibérica. Por el contrario, la orientación norte-sur de los ejes continentales y las grandes barreras geográficas de América, Africa y Australasia no permitieron la difusión y adaptación tecnológica, o la hicieron mucho más difícil. Por ende, las tecnologías inventadas dentro de estos continentes encontraron muchas dificultades para difundirse, traspasando barreras geográficas y ecológicas. Por ejemplo, el maíz tomó muchos miles de años para difundirse desde México hacia el norte, hasta el Valle del Mississippi, ya que se tuvo que adaptar a diferentes condiciones ecológicas a medida que avanzaba por diferentes latitudes. El tipo de 


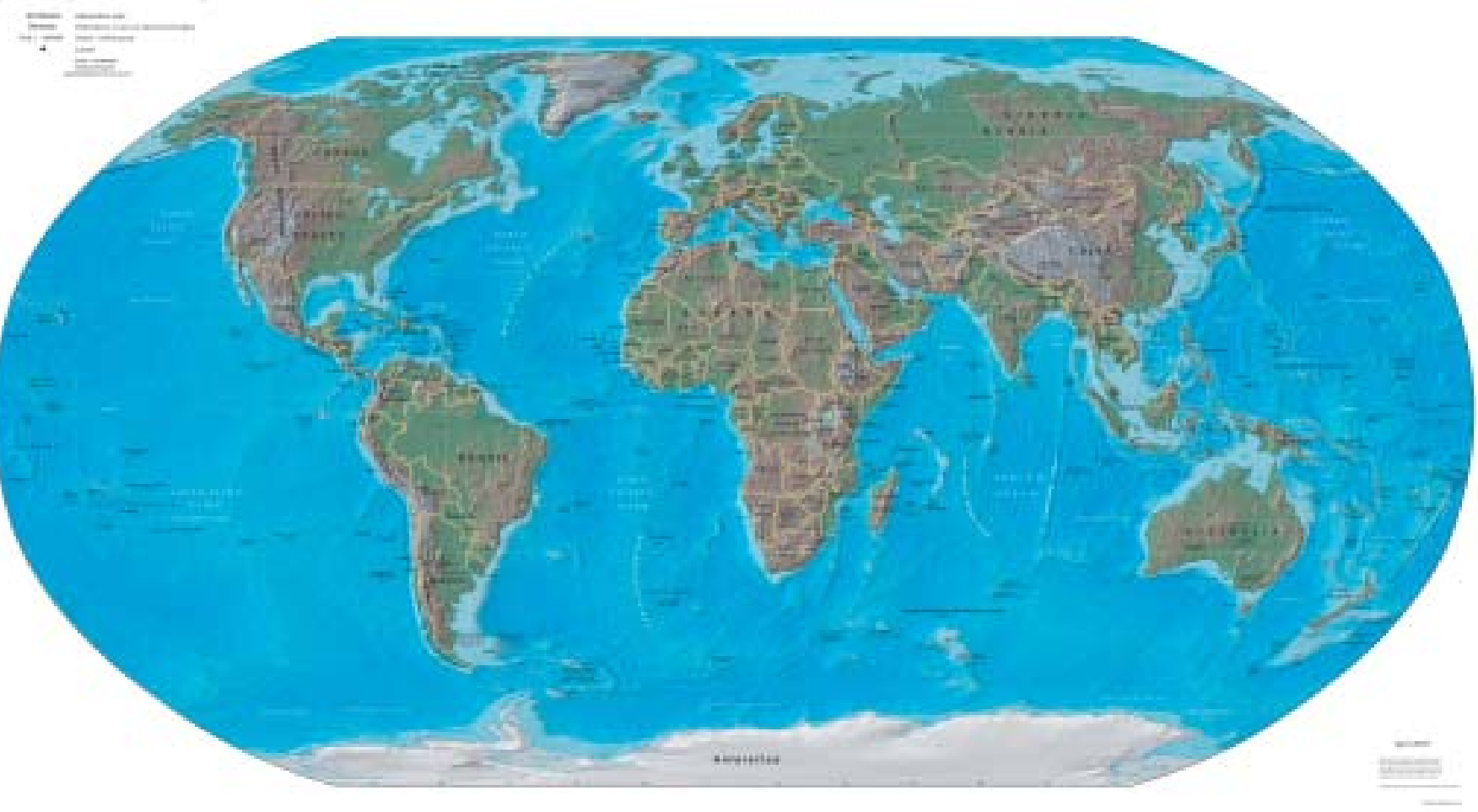

Forma de los continentes: El eje continental este-oeste de Eurasia con su homogeneidad ecológica permitió la difusión y adaptación de los cultivos, los animales, las ideas y la tecnología.

maíz adaptado a las condiciones ecológicas del centro de México germina muy temprano y, por lo tanto, se demora demasiado en crecer en las planicies del centro de América del Norte. El caso de los auquénidos domesticados por las culturas de los Andes centrales (llamas y alpacas) es paradigmático de las dificultades impuestas por la geografía americana al avance tecnológico, éstos nunca se difundieron desde los Andes centrales hacia el Valle de México. En el Viejo Mundo, el desierto del Sahara representó una barrera insoslayable para que los avances agrícolas desarrollados en la media luna fértil pudieran difundirse en el Africa subsahariana. Pero aun cuando este patrón agrícola se hubiese podido difundir, éste no se hubiera podido desarrollar, ya que la agricultura templada no florece en los climas tropicales.

Como un ejemplo del contacto entre dos sociedades de desarrollo asi- 
descendientes de las etnias originarias las que dominan el paisaje demográfico americano. Por consiguiente, nos podemos preguntar: ¿por qué la historia ocurrió de esta manera? ¿Por qué no fueron los incas, los aztecas,o los ashanti los que conquistaron Africa y trajeron a los europeos como esclavos al Nuevo Mundo? La mayoría de las personas tal vez piense: es porque los europeos eran más inteligentes y tenían la iniciativa y la motivación para emprender la conquista del Nuevo Mundo, mientras que las etnias originarias no tenían tal capacidad intelectual o no tenían el empuje. Aunque no existe ninguna evidencia científica de superioridad intelectual entre los europeos y los pueblos originarios, los europeos fueron los que emprendieron esta empresa y, por lo tanto, debe haber otra explicación.

\section{ORIGEN DE LA AGRICULTURA}

Desde que la agricultura fue inventada en la media luna fértil hace aproximadamente unos 12.000 años, durante la revolución del neolítico, se ha desarrollado en por lo menos otros cinco lugares alrededor del globo: China, Nueva Guinea, América del Norte, México y los Andes Centrales. La media luna fértil comprende hoy la región del Medio Oriente ocupada por los estados modernos de Irak, Irán y Siria, especialmente la región entre los ríos Tigris y Eufrates. El comienzo de la agricultura fue un paso importante en el desarrollo de lo que llamamos civilización. Para un pueblo de cazadores y recolectores nómadas no tiene ningún sentido desarrollar la escritura, por decir la escritura cuneiforme. Si estos recolectores se tienen que desplazar por el territorio cada tres semanas en busca de alimento, ellos ya tienen bastante trabajo en acarrear sus implementos básicos, por lo tanto no tienen ningún uso para las tabletas de arcilla. Pero una vez que un pueblo se organiza y asienta en comunidades agrícolas comenzará a desarrollar una civilización. De esta forma se iniciarán los sistemas de gobierno, los mecanismos de producción y de almacenamiento de alimentos, la tecnología aplicada al control del medio ambiente, la aparición de las artes, etc. También aparecerá la necesidad de producir herramientas de metal, se tendrá que aprender a domar y domesticar los caballos como medio de transporte, etc. Junto con la domesticación de los animales comenzará la evolución de gérmenes mortales como la viruela y el sarampión, que desempeñaron un papel crucial en la conquista europea del Mundo Nuevo. Efectivamente, fueron estos y otros gérmenes los que diezmaron al 95 por ciento de los pueblos originarios americanos. Estos gérmenes aparecieron en las sociedades agrícolas que se desarrollaron en la media luna fértil y en la China hace 11.000 años.

Las culturas que habitaban la media luna fértil fueron privilegiadas. Las 


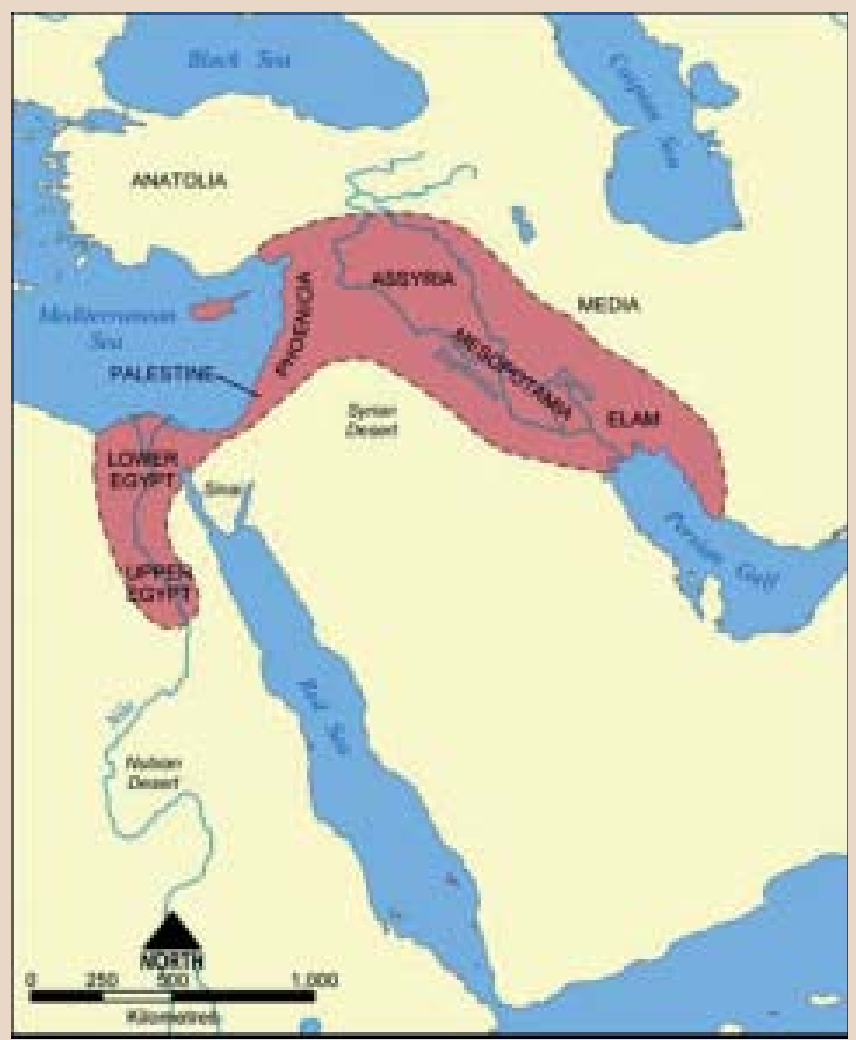

Mapa de la fértil media luna, cuna de la civilización euroasiática.

plantas silvestres de que ellos disponían para domesticar eran fáciles de dominar, crecían rápido y tenían las semillas más grandes. De hecho, la agricultura se desarrolló tempranamente en la media luna fértil porque tenía un clima favorable al crecimiento de las plantas anuales de autopolinización y porque, especialmente allí, se daban los antepasados silvestres de los cereales ricos en proteínas y las leguminosas adecuadas para la domesticación. Sin embargo, este tipo de plantas nativas no se encontraba disponible en los trópicos, en las planicies americanas o en la Patagonia. La media luna fértil era, según se informa, rica en distintas variedades silvestres de trigo y de cebada. La mayor densidad de la semilla -la parte que contiene los nutrienteses uno de los rasgos que determina la aptitud de una planta silvestre para ser domesticada. Estudios contemporáneos han confirmado que 32 de las 56 gramíneas que contienen las semillas más densas que hay son nativas de la 


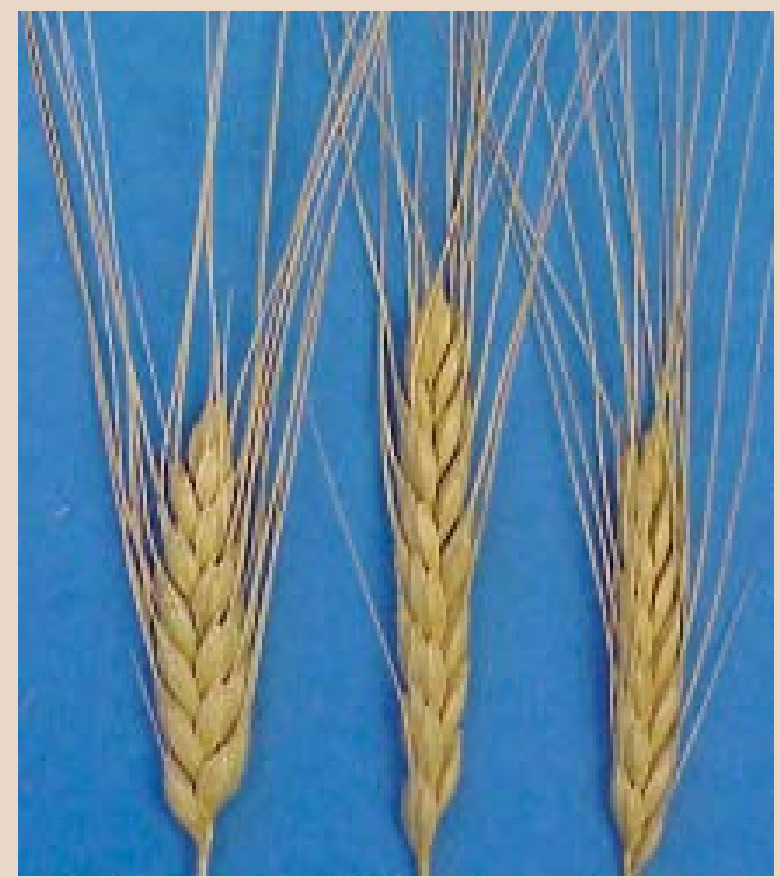

Agricultura: La domesticación de plantas comenzó tempranamente en Eurasia. Por ejemplo, el trigo tipo Emmer fue uno de las primeras plantas silvestres domesticadas en el Medio Oriente durante el Neolítico.

media luna fértil. Solamente cuatro de estas plantas se encuentran en Africa subsahariana y 11 en América.

El cambio de la caza-acopio al cultivo de la tierra, como el profesor Diamond discute (de seguro correctamente), no fue la inspiración de un genio solitario; al contrario, fue un cambio incremental y, en gran parte, imprevisto. Los cazadores-recolectores primero tomaron nota de las plantas más deseables, después comenzaron a volver a las especies más vigorosas de esas plantas, entonces se instalaron permanentemente cerca de esas especies, después comenzaron a cuidarlas, y después conscientemente las sembraron para futuras cosechas.

Más eficaces que la caza o la recolección, los cultivos rindieron excedentes de alimento que permitieron claros aumentos en la densidad demográfica. Por ende, la seguridad alimentaria permitió el surgimiento de centros urbanos y de clases no agrícolas especializadas, tales como escribanos, artistas, sacerdotes, intelectuales, ingenieros, soldados y, eventualmente, una 
burocracia gubernamental. Las sociedades agrícolas sedentarias tendieron hacia una mayor complejidad social, la producción de nuevas ideas e invenciones, la innovación sinérgica y la dominación militar de sus vecinos. Como lo han informado una serie de estudios contemporáneos sobre la función del espacio en la vida social, la aglomeración de la población y de las actividades económicas en ciudades y regiones crea, por sí misma, estímulos sinérgicos que incentivan la innovación y el desarrollo. El geógrafo americano Edward Soja, en su reciente libro Postmetropolis: Critical Studies of Cities and Regions (2000), denomina synekism a este proceso espacial de estimulación por proximidad territorial. Por otra parte, Diamond discute específicamente que el nacimiento de la urbanización comenzó en la media luna fértil mucho antes que en otra parte del globo debido, como lo hemos dicho antes, a la presencia de una gran diversidad de plantas y animales domesticables. Entonces, la desigual distribución geográfica de plantas y animales domesticables (más que cualquier superioridad inherente de sus habitantes) condujo a que el Medio Oriente se transformara en la "cuna de la civilización”. Sin embargo, otras partes del mundo nunca tuvieron esta oportunidad, y la falta de los recursos clave para el desarrollo de una sociedad agrícola sedentaria selló sus destinos. Unas no tenían plantas nativas que pudieran ser domesticadas; otras tenían muy pocas y las comenzaron a cultivar muy tarde, de modo que fueron sobrepasadas abrumadoramente por los descendientes de los euroasiáticos que ya habían comenzado a urbanizarse hace unos 9.000 años ${ }^{3}$.

Entonces, dicho patrón de agricultura mixta permitió a los euroasiáticos sostener altas densidades de población en sus asentamientos. El enorme tamaño y las altas densidades de población de Eurasia hicieron que concentrara la mayor parte de la población mundial, lo que permitió -a su vezque dicho continente generara la mayor parte de los inventos y de las innovaciones tecnológicas producidas por estímulos de proximidad territorial. La facilidad de las comunicaciones y de la difusión a lo largo del territorio permitió que las invenciones generadas en un lugar se dispersaran con relativa rapidez a otro. La veloz y amplia difusión de los adelantos tecnológicos, a su vez, concedieron a los euroasiáticos la rueda, el caballo, los textiles, la metalurgia avanzada, la navegación de largo alcance, el Estado, la pólvora y las armas de hierro.

\footnotetext{
${ }^{3}$ Recientes descubrimientos arqueológicos han señalado que el primer centro urbano del mundo es la ciudad neolítica de Çatalhöyük, en la planicie de Anatolia, Turquía (7000 a.d.n.e.). Los resultados de las próximas excavaciones en este sitio aportarán importantes elementos para avanzar en nuestra comprensión de los orígenes de la agricultura y civilización. Para más información de este proyecto arqueológico, véase la página web: <http://catal.arch.cam.ac.uk/catal/ catal.html>.
} 


\section{DOMESTICACION DE ANIMALES}

Tan importante como el cultivo de la tierra fue, según el profesor Diamond, la presencia de grandes animales domesticables que proporcionaban las proteínas, el transporte y la energía de alta calidad para el trabajo. El desarrollo de los carros de arrastre nunca ocurrió en el Nuevo Mundo: la llama de los Andes centrales nunca fue enganchada a las ruedas de juguete de los aztecas, pues se hallaban separadas por la selva tropical del Istmo de Panamá. De nuevo, Eurasia fue bastante afortunada al tener la mayoría de los grandes mamíferos herbívoros salvajes que podían ser domesticados: ovejas, cabras, vacas, cerdos y caballos. Africa tenía el búfalo y la cebra, pero las cebras y los búfalos africanos son irritables y difíciles de domar, como lo han comprobado intentos contemporáneos de domesticación de dichos animales. De esta forma, podemos adjudicar la subsiguiente dominación de Africa por Europa como un "accidente biogeográfico." Los animales y las plantas domesticados confirieron una ventaja final y decisiva a las culturas euroasiáticas, útiles en la conquista de nuevas tierras.

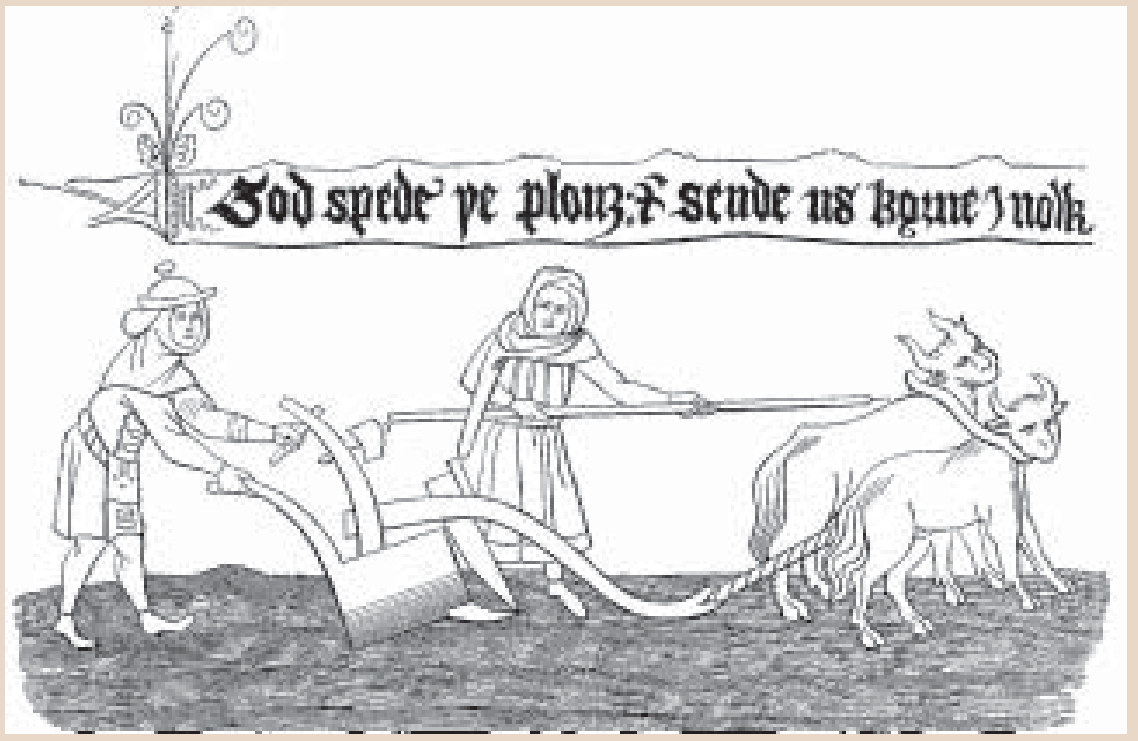

Importancia del ganado el la agricultura europea. Grabado inglés del siglo XIV del poema God Spede ye Plough. 


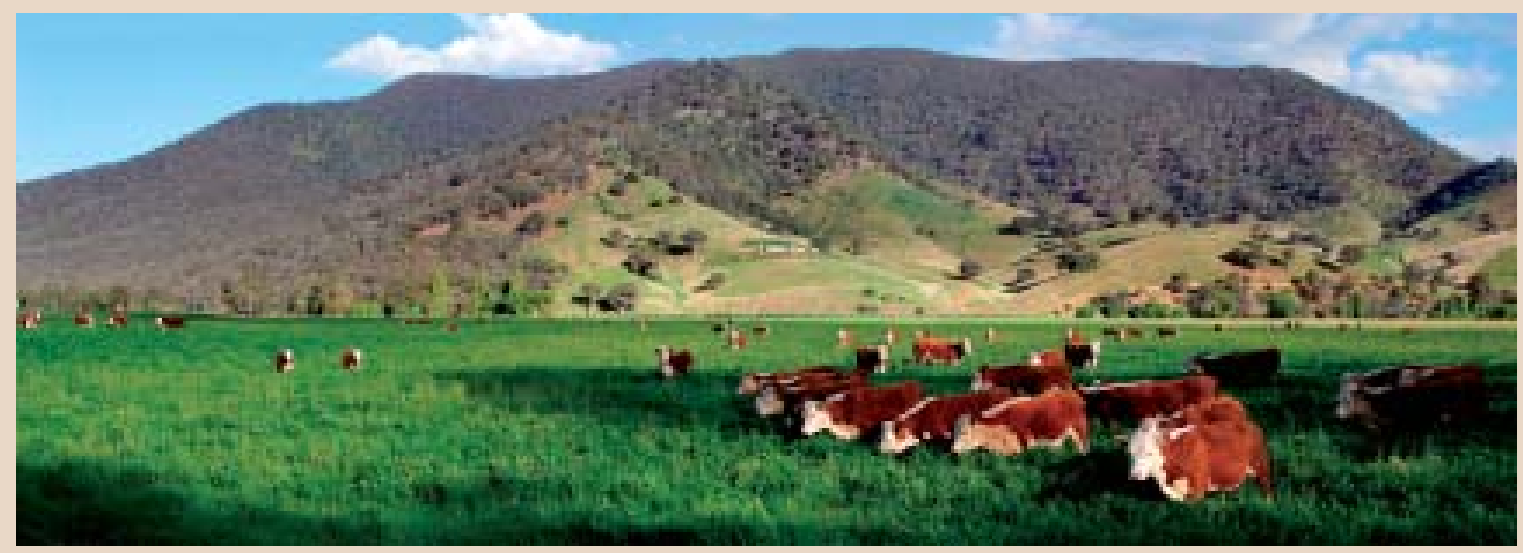

Ganadería: El ganado vacuno (ganado tipo Hereford en la foto) es el animal más emblemático de los euroasiáticos, desciende de un antiguo ancestro salvaje nativo que vivió en Eurasia y en el norte de Africa al final de la última glaciación, fue domesticado en la fértil media luna en el Neolítico (8000 a.d.n.e.).

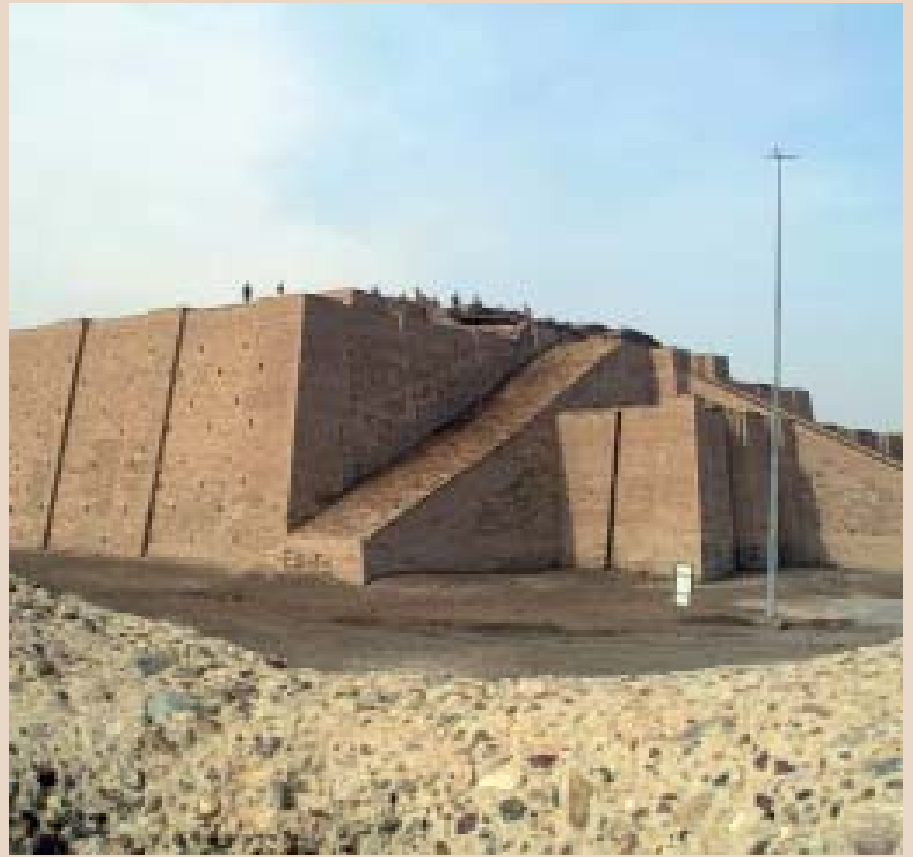

Ciudades y civilizaciones: los cultivos rindieron excedentes de alimento que permitieron claros aumentos en la densidad demográfica y, por ende, una mayor complejidad social. La evidencia más temprana de esto se encuentra en la media luna fértil. Allí, se desarrollaron las primeras aldeas, y luego, las primeras ciudades. En la foto, el gran Ziggurat de la antigua Mesopotamia.

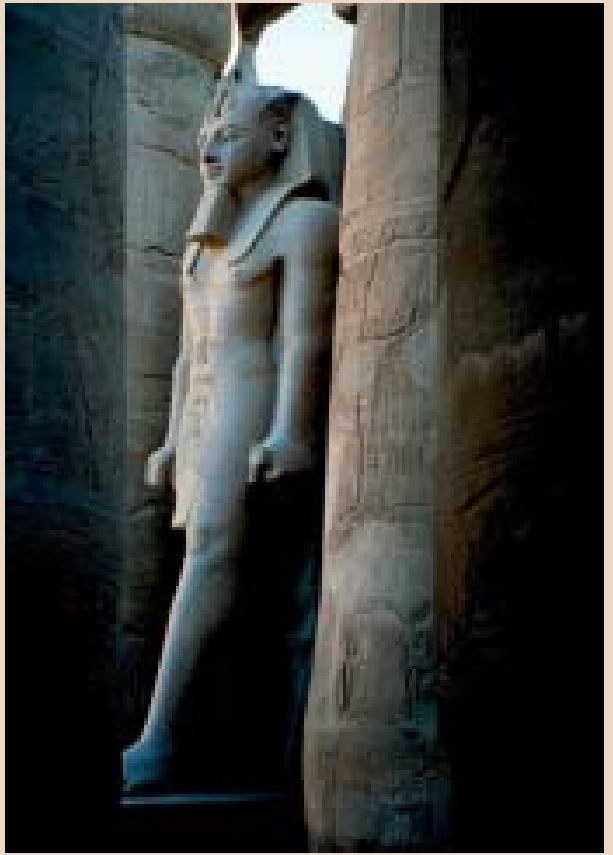

Estatua del Faraón Amenhotep III, Templo Luxor, Egipto. 
No es que los antiguos habitantes de la media luna fértil fueran más dotados o más inteligentes y vislumbraron primeramente las ventajas de la agricultura. Ellos no tuvieron ninguna idea de estas necesidades. En su lugar, la supremacía del desarrollo tecnológico de los euroasiáticos fue una consecuencia involuntaria, sin intencionalidad -una unintended consequence en el lenguaje de la epistemología de las ciencias sociales anglosajonas. Eurasia, en general, y la media luna fértil, en particular, contaban con los antepasados silvestres de las más valiosas especies vegetales y animales susceptibles de ser domesticadas. El trigo y la cebada, el antepasado de los vacunos, las ovejas, las cabras, los cerdos y los caballos, todos eran nativos de la media luna fértil. Además, la configuración geográfica del continente permitió la rápida difusión de dichas plantas y animales, y de otros adelantos tecnológicos, gatillando un intensivo desarrollo de las fuerzas productivas, lo que, unido al temprano desarrollo de las armas (de hierro y biológicas), les proporcionó a los descendientes de los antiguos euroasiáticos una supremacía militar que, últimamente, les otorgó el control geopolítico del globo.

¿Por qué los aborígenes australianos siguen siendo cazadores-recolectores? Porque nadie ha podido hoy domesticar los canguros, los únicos grandes mamíferos salvajes de Australia. La única planta de Australia que se ha domesticado son las nueces de macadamia, pero no se puede alimentar a toda una civilización sedentaria sólo con nueces de macadamia. Pero sí se puede hacer con el trigo, la cebada, las arvejas, las lentejas, etc. Esta es la razón por la que los aborígenes australianos siempre fueron cazadores-recolectores y los euroasiáticos fueron los primeros cultivadores y ganaderos. Cuando los europeos construyeron una sociedad industrializada en Australia, tuvieron que importar todos los elementos claves (tales como los cultivos y la tecnología) desde afuera.

\section{DESARROLLO DE LOS GERMENES}

Diamond argumenta que los gérmenes que producen las enfermedades contagiosas más mortales que afectan a los humanos fueron un subproducto de la domesticación de los animales. En efecto, éste es uno de los descubrimientos más sorprendentes al que se ha llegado con el actual desarrollo de la biología molecular. Ahora sabemos que la viruela, el sarampión y otras enfermedades epidémicas de los seres humanos se desarrollaron a partir de enfermedades de nuestros animales domésticos con los cuales entramos en contacto íntimo cuando comenzamos a domesticarlos hace 11.000 años. La viruela pudo haberse desarrollado de una enfermedad de nuestros camellos domésticos. El sarampión se desarrolló ciertamente de una enfer- 
medad de nuestros ganados domésticos. Las poblaciones euroasiáticas se vieron expuestas a estas enfermedades y, gradualmente, desarrollaron resistencias inmunitarias y genéticas contra ellas. Pero las culturas de otras latitudes (como las etnias originarias americanas) sin estos grandes animales domésticos, con la excepción de las llamas y alpacas, no desarrollaron estos gérmenes ni la inmunidad a ellos. Cuando llegaron los europeos portando en su dossier biológico la viruela, el sarampión y otros gérmenes mortales, los pueblos originarios murieron antes de que pudieran incluso alcanzar el campo de batalla: los gérmenes de Eurasia los mataron. Esta es la razón fundamental de cómo la geografía inclinó la balanza en el desarrollo de ciertas sociedades del mundo.

De esta forma, la domesticación de los animales suministró a los euroasiáticos resistencias inmunitarias a dichas enfermedades. Los animales domesticados producen microbios mortales al hombre. Pero con el paso del tiempo, los portadores humanos desarrollan inmunidades a estos gérmenes $y$, al mismo tiempo, estos organismos evolucionaron para no matar demasiado rápido a sus hospederos humanos. Sin embargo, los pueblos originarios del Nuevo Mundo, de Africa y de Australasia no domesticaron estos animales y no estuvieron expuestos a los gérmenes de enfermedades transmisibles de los europeos y, por ende, sucumbieron en masse durante la edad de la exploración europea. El caso más paradigmático de este proceso, por supuesto, fue la declinación de la población de los incas y de los aztecas por los gérmenes que acompañaban a los conquistadores españoles. Una vez más, la audacia y la inteligencia no estuvieron relacionadas con el éxito militar de los europeos.

En suma, el argumento propuesto por Diamond para explicar por qué fueron los descendientes de los euroasiáticos los que conquistaron Perú, México, Australia y gran parte de Africa, es el siguiente: las sociedades de Eurasia adquirieron ventajas claves al desarrollar las semillas, los animales domesticados y la resistencia a los gérmenes de enfermedades mortales. La geografía de Eurasia posibilitó la difusión de la agricultura, lo que facilitó, a su vez, el desarrollo de la urbanización y la creación de una clase de especialistas no agrícolas. Tal temprano desarrollo fue amplificado de manera cada vez mayor por la innovación tecnológica, especialmente de las armas de hierro. De esta manera, para 1492, los descendientes de los antiguos euroasiáticos habían concentrado extraordinarias ventajas sobre otras culturas. Más aún, dicho patrón de desarrollo los lanzó hacia una imperativa expansión geográfica en búsqueda de nuevos mercados y recursos. Así, llegaron a otras tierras para ganar gloria y hacerse ricos; en el proceso, conquistaron y dominaron a diversos pueblos y etnias con sus armas superiores, principalmente con las enfermedades del Viejo Mundo, para las cuales los pueblos nativos no tenían resistencias inmunitarias. 


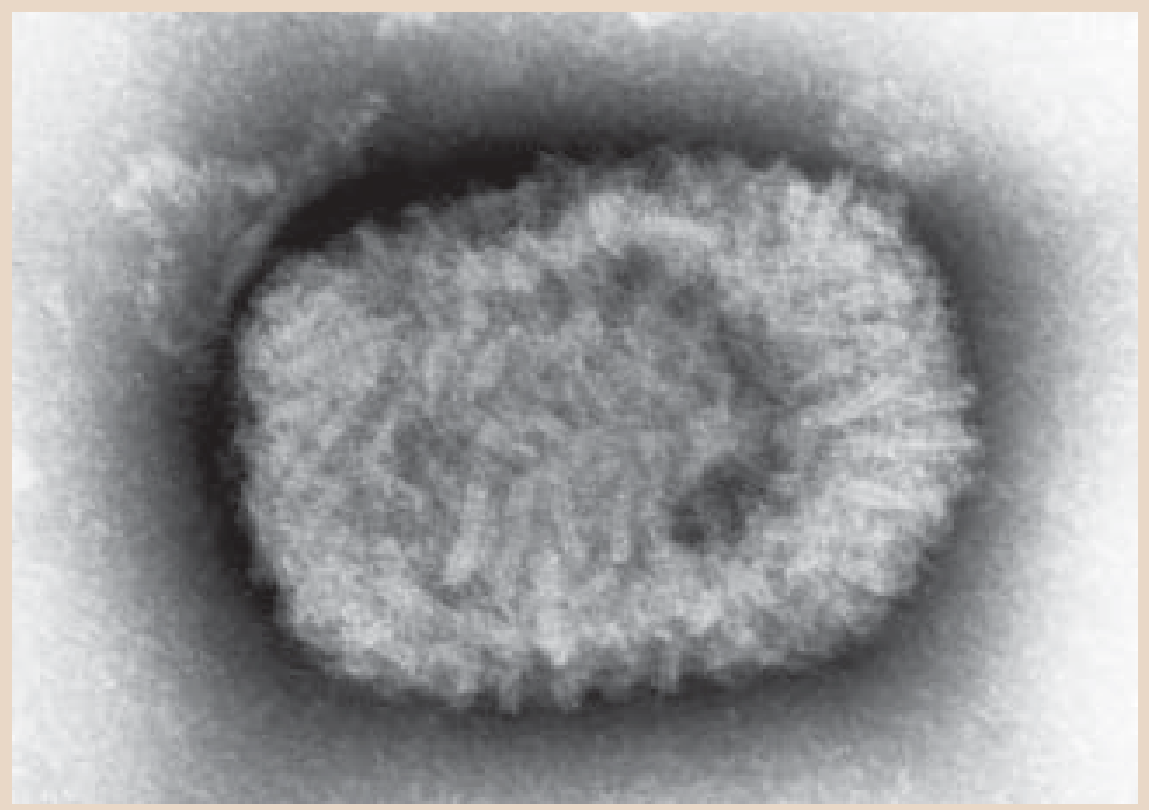

Gérmenes de enfermedades infecciosas: las armas de acero no pueden explicar, por sí solas, la rapidez con que las poblaciones nativas del Nuevo Mundo sucumbieron en pocas generaciones. Fueron las enfermedades tales como la viruela las responsables de tal destrucción. Algunos académicos estiman que aproximadamente 20 millones de personas pueden haber muerto en los años que siguieron a la invasión Europea - más del 95\% de la población americana (virus de la viruela, negativo).

Sin embargo, ¿por qué no fue la civilización china, la hindú o la del islam la que logró expandir su cultura y dominio al resto de Eurasia y del mundo? Si las invenciones decisivas para el desarrollo de la civilización occidental, como la agricultura y la urbanización, y muchos otros adelantos tecnológicos (tales como los instrumentos de navegación, la astronomía, la pólvora, la impresión en bloques, los números, la medicina, la química y la geometría), no se produjeron en Europa sino en otros rincones de Eurasia, ¿por qué, entonces, fueron los europeos los que últimamente lograron dominar al resto del mundo? En tal caso es válido preguntar: ¿Por qué Europa? ¿Por qué no China? ¿Por qué, y cómo, la civilización europea adquirió el dominio decisivo sobre el resto de Eurasia y del mundo partir del siglo XVI? Diamond no tiene una respuesta para esta pregunta. Guns, Germs, and Steel, es un libro que explica por qué los euroasiáticos, en general, conquistaron América, Africa y Australasia a partir del siglo XVI. No es un libro que explique por qué los europeos, en particular, conquistaron Asia y el resto del mundo en los últimos 500 años. 
Una de las críticas que ha recibido Guns, Germs, and Steel es que el libro, a pesar de la intencionalidad explícita de su autor por elaborar una síntesis global de causalidad histórica del desarrollo de la humanidad -como la desarrollada por el historiador británico Arnold Toynbee en los 12 volúmenes de su A Study of History (1934-54) - no contempla fenómenos políticos y/o ideológicos dentro de su aparato explicatorio. Usualmente, cuando un científico de las ciencias naturales vuelve su atención académica hacia la historia y la antropología para invocar causalidades medioambientales en el desarrollo de las civilizaciones, resulta muy fácil acusarlo de determinismo, de funcionalismo, o de los dos. Sin embargo, en nuestra opinión, Diamond sale victorioso desde las tortuosas aguas del determinismo ambiental. Para él, las ideas y la cultura, por supuesto, son importantes en el desarrollo de las sociedades humanas. No obstante, el autor argumenta que las ideas, la tecnología y la cultura sólo pueden desarrollarse allí donde prevalezcan las condiciones ambientales adecuadas. Allí donde las culturas se hayan constituido en sociedades organizadas y se hayan asentado en centros urbanos que dependan (y a la vez que sean el fruto) del desarrollo de la agricultura. Así pues, para Diamond, en el temprano desarrollo de la humanidad, la geografía (especialmente la desigual distribución de plantas y animales que pueden ser domesticados) y las condiciones ecológicas, fueron los factores decisivos que determinaron el grado de desarrollo alcanzado por las distintas civilizaciones y, últimamente, fijaron el destino de las sociedades humanas. El libro es un avance importante en nuestra comprensión del temprano desarrollo del pasado humano; empero, lo más encomiable es que, desde la perspectiva epistemológica medioambiental, presenta un argumento convincente en contra de las teorías deterministas de superioridad racial. Es un libro notablemente legible que demuestra cómo la historia y la biología pueden enriquecerse mutuamente para producir una comprensión más profunda de la condición humana.

\section{REFERENCIAS}

Diamond, Jared. 1998. Guns, Germs, and Steel: The Fates of Human Societies. New York: w.w. Norton \& Company, 1997. Traducción de Fabián Chueca, Armas, gérmenes y acero: La sociedad humana y sus destinos. Editorial Debate.

Soja, Edward W. 2000. Postmetropolis: Critical Studies of Cities and Regions. Oxford; Malden, Mass.: Blackwell Publishers.

Toynbee, Arnold Joseph. 1934-1954. A study of History. London: Oxford University Press, H. Milford (12 vols.).

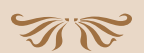

